\title{
The Bioenergetics of Exercise
}

\section{P. Darrell Neufer}

East Carolina Diabetes and Obesity Institute, Departments of Physiology and Kinesiology, Brody School of Medicine, East Carolina University, Greenville, NC 27834

Correspondence: neuferp@ecu.edu

Animals possess a remarkable ability to perform physical activity over a wide range of workloads and durations, reflecting both the inherent efficiency and large reserve capacity of energy transfer systems. Deciphering how different organ/physiological systems respond to the acute and chronic demands of exercise depends on a foundational understanding of the redox and bioenergetic principles that underlie the flow of electrons in living systems and its coupling to ATP synthesis. The purpose of this review is to set the stage to cover (1) the thermodynamic driving forces responsible for generating and maintaining the energy charge that establishes and sustains life for cells, and (2) how cellular energy transfer systems respond to changes in energy demand to ensure energy charge is preserved.

\begin{abstract}
All organisms require an input of energy A to generate and sustain life. The ultimate source of that energy is sunlight, which is captured by plants, algae, and photosynthetic bacteria to synthesize complex organic compounds that are ingested and broken down by nonphotosynthetic organisms. Basic science texts often refer to the energetics of life as emanating from the transformation of energy from food into useful work, focusing on the biochemical pathways responsible for the catabolism of organic compounds in cells, ending with the mitochondrial oxidative phosphorylation system (OXPHOS). This approach, although accurate, often fails to convey the thermodynamic driving forces that actually bring a cell to life energetically. For example, how is the energy transformation that is necessary to establish cellular life generated in the first place? Is it driven by the breakdown of ingested organic molecules, or are there other driving forces? What are the nor-
\end{abstract}

mal driving forces for flux through catabolic pathways? How is cellular energy charge maintained in the face of increased energy demand? The next section covers the basic principles of bioenergetics-the free energy forces and conversions that are used to establish and maintain energy homeostasis for all cells. That is followed by a section on how energy charge is maintained in cells during periods of increased energy demand, as occurs during exercise, through the integration of energy transfer systems.

\section{SETTING THE CHARGE}

\section{Oxygen's Electronegativity as the Primary Driving Force}

In the 1780s, Luigi Galvani discovered that the legs of a frog hemicorpus could be stimulated to contract by applying an electrical current. To fans of the occult, this gave birth to the idea

Editors: Juleen R. Zierath, Michael J. Joyner, and John A. Hawley

Additional Perspectives on The Biology of Exercise available at www.perspectivesinmedicine.org

Copyright (C) 2018 Cold Spring Harbor Laboratory Press; all rights reserved; doi: 10.1101/cshperspect.a029678

Cite this article as Cold Spring Harb Perspect Med 2018;8:a029678 
P.D. Neufer
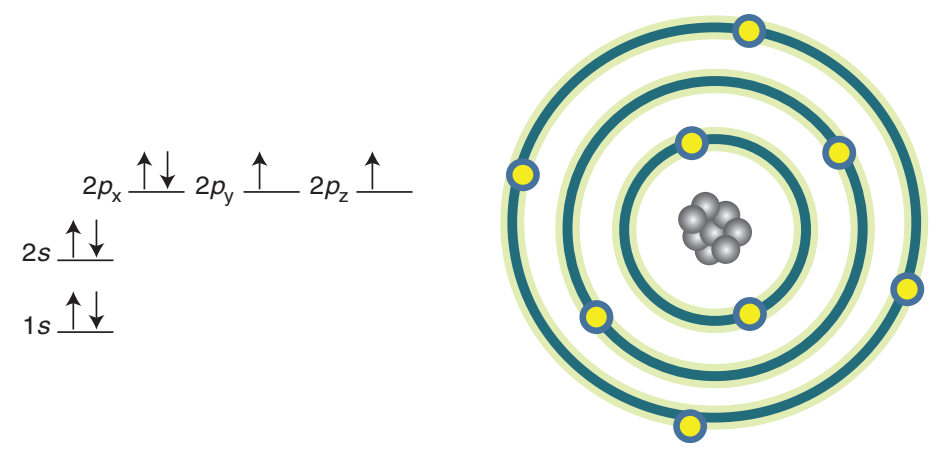

Figure 1. Electron configuration of the oxygen atom. Depicted is the configuration of electrons in the orbitals surrounding the oxygen atom. Arrows represent electrons with a specific spin resonance.

that electricity could be used to bring inanimate biological material to life, as popularized by Mary Shelley's novel Frankenstein published early the next century. "Galvanism"- the application of an electric current to stimulate a muscle to contract—gave birth to the modern study of electrophysiology. In physics and chemistry, however, "galvanism" refers to the conduction of electrical current between two molecules with differing electronegativities (i.e., the tendency to attract electrons).

The oxygen atom has the second highest electronegativity of all elements (fluorine is the most electronegative), a property that serves as the primary driving force of bioenergetics. Electronegativity is a function of the nuclear charge of the atom relative to the number and location of electrons in the atomic shells. The oxygen atom contains eight protons in its nucleus and eight electrons within its orbitals in the configuration shown in Figure 1.

Moving out from the nucleus, electrons with opposite spin resonances (direction of arrow) pair, filling each successive orbital. For the oxygen atom, the $2 p$ orbital contains two unpaired electrons with the same spin resonance, making it two electrons short of filling the $2 p$ orbital and thus accounting for its high electronegativity (Fig. 1). In fact, the oxygen atom does not exist in nature, stabilizing its outer shell by sharing unpaired electrons with another oxygen atom to form an oxygen molecule $\left(\mathrm{O}_{2}\right)$, or by combining with two hydrogen atoms to form a water molecule $\left(\mathrm{H}_{2} \mathrm{O}\right)$. The electronegativity of the oxygen atom is also much greater than hydrogen. Thus, it is this difference in electron affinity-the strength of oxygen as a molecular electron magnet-that strongly favors the conversion of $\mathrm{O}_{2}$ to $\mathrm{H}_{2} \mathrm{O}$. This simple chemistry serves as the primary thermodynamic driving force for aerobic metabolism.

\section{Reduction Potential}

The electron affinity of atoms in more complex chemical species is influenced by the surrounding environment and as such cannot be deduced simply from an atom's electronegativity. Proteins contain two common amino acids with reversible affinity for electrons, cysteine, and methionine, each of which contain sulfur. Similar to oxygen, the sulfur atom contains two unpaired electrons in its outer shell ( $3 p)$, accounting for its high electronegativity. However, the electron affinity of sulfur containing amino acids in proteins is influenced by the surrounding molecular environment, and thus is characterized by a different but related property known as reduction potential (redox potential or oxidation/reduction potential). Similar to electronegativity, reduction potential is defined as the tendency of a chemical species to gain an electron(s) - to become more negatively charged or "reduced." A chemical species that loses an elec$\operatorname{tron}(\mathrm{s})$ is said to become "oxidized," because $\mathrm{O}_{2}$ is typically the final electron acceptor in biology.

Reduction potentials are measured in relative terms by a technique known as a half-cell 
The Bioenergetics of Exercise

reaction. Under standard temperature and pressure conditions, two solutions, one containing the simplest redox couple $2 \mathrm{H}^{+} / \mathrm{H}_{2}$ at equilibrium (reference solution) and the second containing equal concentrations (usually $1 \mathrm{M}$ ) of the oxidized and reduced forms of the redox couple of interest (test solution), are connected by an electron conduit and a voltmeter. By convention, the reduction potential of the standard hydrogen electrode is set to zero. If the test solution contains, for example, the $\mathrm{O}_{2} / 2 \mathrm{H}_{2} \mathrm{O}$ redox couple, electrons will flow from the hydrogen half-cell to reduce oxygen to water because the reduction potential of $\mathrm{O}_{2}$ is greater than that of $\mathrm{H}^{+}$, generating a positive reading on the voltmeter. On the other hand, if the test solution contains the $\mathrm{NAD}^{+} / \mathrm{NADH}$ redox couple, then electrons will flow in the other direction from the test solution to reduce $2 \mathrm{H}^{+}$, generating a negative reading on the voltmeter (i.e., the reduction potential of $\mathrm{NAD}^{+}$is less than that of $\mathrm{H}^{+}$) (Fig. 2). It is important to emphasize that reduction potential refers to the tendency of the oxidized form of a redox couple to attract an electron(s) (i.e., an electron magnet), not the tendency of the reduced form to give up an electron(s) (the latter is referred to as the oxidation potential, but is less frequently used to avoid confusion).

Therefore, the reduction potential of $\mathrm{O}_{2}$ is greater than that of $\mathrm{H}^{+}$, which in turn is greater than that of $\mathrm{NAD}^{+}$. In fact, the standard reduction potential at $\mathrm{pH}=7,37^{\circ} \mathrm{C}$, designated $\mathrm{E}^{\mathrm{o}^{\prime}}$ for the $\mathrm{O}_{2} / 2 \mathrm{H}_{2} \mathrm{O}$ redox couple is $\sim 816 \mathrm{mV}$ and for the $\mathrm{NAD}^{+} / \mathrm{NADH}$ redox couple is $\sim-320 \mathrm{mV}$, a difference of more than 1 volt! At the molecular level, this difference in reduction potential between these two particular redox couples represents a tremendous amount of potential energy (i.e., Gibbs free energy difference, $\Delta G$ ) and, as we shall see, is the primary bioenergetic driving force.

\section{Metabolic Accounting}

Before covering how that potential energy is used, consider first the complete catabolism of one molecule of glucose through glycolysis and the tricarboxylic acid (TCA) cycle. All six carbon atoms in glucose are converted to $\mathrm{CO}_{2}$, yielding a little bit of energy in the form of ATP plus 16 hydrogens. The easiest thing for nature to have performed is to simply allow the hydrogens to combine with oxygen to produce water. Instead, those hydrogens, and more specifically the electrons they carry, are captured by electron carrier proteins $\left(\mathrm{NAD}^{+}, \mathrm{FAD}^{+}\right)$during each reaction in glycolysis and the TCA cycle in which hydrogen is liberated, effectively shielding the electrons from oxygen. Once those electrons from glycolysis are shuttled into the mitochondria, the stage is set to make use of that $>1$-volt difference in reduction potential between $\mathrm{NAD}^{+}$and $\mathrm{O}_{2}$.

\section{Using Reduction Potential to Generate Membrane Potential}

The mitochondrial electron transport system (ETS) is a wonder of nature, a molecular engine

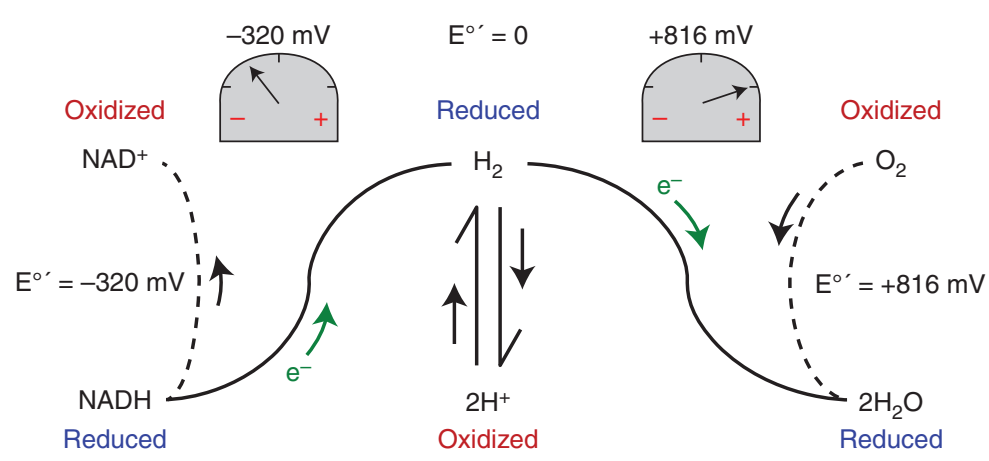

Figure 2. Schematic of half-cell reaction system for determining reduction potential of redox couples. See text for explanation. 
P.D. Neufer

that capitalizes on the potential energy difference between a strong $\left(\mathrm{O}_{2}\right)$ and weak $\left(\mathrm{NAD}^{+}\right)$ electron magnet to increase the yield of ATP by ninefold. The ETS consists of a series of $>20$ redox couples contained within several multiprotein complexes embedded in the mitochondrial inner membrane. There are two features of the ETS that are essential to understanding how the engine works. The first is, similar to a conventional electrical circuit, electron flow through the ETS occurs by default, as long as there is a continuous draw on the circuit (i.e., $\mathrm{O}_{2} \rightarrow 2 \mathrm{H}_{2} \mathrm{O}$ ) and a source of electrons (e.g. $\mathrm{NADH})$. The second is that three of the complexes (I, III, and IV) in the ETS couple electron flow to proton pumping, such that neither can occur without the other. Both of these features are considered in detail below.

Although typically described as beginning with the transfer of electrons from $\mathrm{NADH}$ to complex I, it is functionally more useful to think of the ETS as beginning with $\mathrm{O}_{2}$ because it is the high reduction potential of the $\mathrm{O}_{2} /$ $2 \mathrm{H}_{2} \mathrm{O}$ redox couple that is drawing electrons; that is, setting the "pull" on the system. $\mathrm{O}_{2}$ $\left(\mathrm{E}^{\mathrm{o}^{\prime}}=\sim 816 \mathrm{mV}\right)$ initially draws electrons from a redox couple with a lower $\mathrm{E}^{\mathrm{o}^{\prime}}$, the cytochrome $a_{3}$ electron carrier in complex IV $\left(\mathrm{E}^{\mathrm{o}^{\prime}}=\sim 600 \mathrm{mV}\right)$, which in turn draws electrons from a redox couple just upstream $\left(\mathrm{E}^{\mathrm{o}^{\prime}}=\sim 300 \mathrm{mV}\right.$ ) and so on back through each of the complexes. Although an oversimplification, the reduction potential of each electron carrier is less than the next carrier downstream (i.e., toward $\mathrm{O}_{2}$ ), and higher than the carrier upstream, creating a draw of electrons through the entire redox potential span back to the $\mathrm{NAD}^{+} /$ NADH redox couple $\left(\mathrm{E}^{\mathrm{o}^{\prime}}=-320 \mathrm{mV}\right)$. It is important to appreciate that this is an open electric circuit, meaning that as long as $\mathrm{O}_{2}$ and $\mathrm{NADH}$ are not rate limiting and a regulator is not applied, electron flow is wide open.

Despite the constant draw of electrons by $\mathrm{O}_{2}$, mitochondrial oxygen consumption of course is very dynamic and responsive to demand-a function of the second feature of the system. The simplest way to grasp this is to do a thought experiment. Imagine starting from scratch with the ETS embedded in an artificial membrane vesicle and a constant supply of $\mathrm{O}_{2}$. As soon as a source of electrons (i.e., NADH generating substrate) is introduced, electrons will start flowing, $\mathrm{O}_{2}$ will start being consumed, and $\mathrm{H}^{+}$will start being pumped out of the matrix at complexes I, III, and IV (Fig. 3A). Initially, the rate at which all three are occurring will essentially be wide open, as described in the previous paragraph. As protons accumulate along the outer surface of the inner membrane, however, a positive charge and $\mathrm{H}^{+}$concentration difference begin to develop across the membrane, known as the proton motive force ( $\Delta \mathrm{p}$ or PMF) (Fig. $3 \mathrm{~B}$ ). Because the capacitance (i.e., ability to separate an electrical charge when a voltage is applied) of biological membranes is high, even a small difference in ion concentration generates a significant electrical potential across the membrane. Thus, although possessing both an electrical (i.e., charge difference) and chemical (i.e., concentration difference) component, it is the membrane potential $(\Delta \Psi)$ that accounts for the vast majority of the PMF. Recognize that the Gibbs free energy difference in reduction potential between the $\mathrm{O}_{2} / 2 \mathrm{H}_{2} \mathrm{O}$ and $\mathrm{NAD}^{+} / \mathrm{NADH}$ redox couples $\left(\Delta \mathrm{G}_{\text {redox }}\right)$ is being used to drive the generation of a different form of free energy across the membrane, the $\Delta \mathrm{G}_{\mathrm{PMF}}$. As the process continues, however, the accumulation of $\mathrm{H}^{+}$on the outer surface of the membrane, and therefore the increasing $\Delta \mathrm{G}_{\mathrm{PMF}}$, begins to create a backpressure on the proton pumps, gradually slowing the rate of electron flow and respiration (Fig. 3B). Eventually, $\Delta \mathrm{G}_{\mathrm{PMF}}$ builds until the backpressure counterbalances the driving pressure $\left(\Delta \mathrm{G}_{\text {redox }}\right)$ of the proton pumps. At this point, $\Delta \mathrm{G}_{\mathrm{PMF}}=\Delta \mathrm{G}_{\text {redox }}$ and the rates of electron flow, proton pumping, and $\mathrm{O}_{2}$ consumption slow to zero. The ETS reaches a standstill (i.e., static head), not because it is defective, but because opposing free energy forces reach a balance point against each other (Fig. 3C).

If $\Delta \mathrm{G}_{\text {redox }}$ sets the current and $\Delta \mathrm{G}_{\mathrm{PMF}}$ functions as a brake on electron flow, then it should be apparent that getting respiration going again will require easing off on $\Delta \mathrm{G}_{\mathrm{PMF}}$. In reality, functioning mitochondria never reach a static head because the mitochondrial inner mem- 

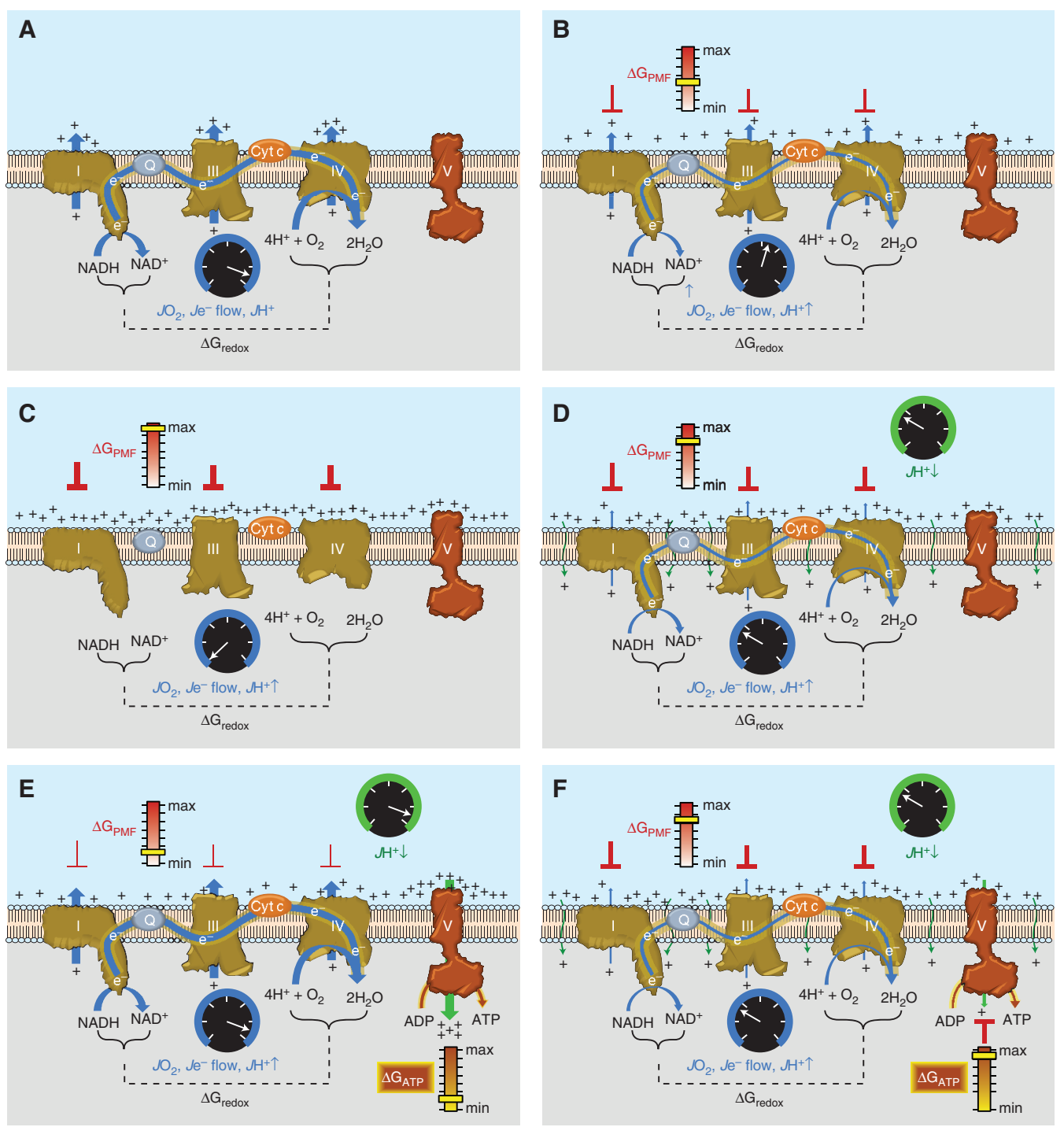

Figure 3. Sequential schematic detailing the driving forces governing the control of mitochondrial oxidative phosphorylation. The reader is encouraged to refer to the text for additional details. $(A)$ Conceptual representation of an electron transport system (ETS) embedded within an artificial membrane vesicle. Addition of reducing equivalents $(\mathrm{NADH})$ generates immediate and rapid rates of $\mathrm{O}_{2}$ consumption $\left(\mathrm{JO}_{2}\right)$, electron flow ( $\mathrm{Je}^{-}$flow), and proton pumping $\left(\mathrm{JH}^{+} \uparrow\right.$ ) at complexes I, III, and IV driven by the high $\Delta \mathrm{G}_{\text {redox }}$ between the $\mathrm{O}_{2} /$ $\mathrm{H}_{2} \mathrm{O}$ and $\mathrm{NAD}^{+} / \mathrm{NADH}$ redox couples. $(B)$ As protons accumulate on the outer surface of the membrane, an electrochemical gradient or proton motive force (PMF) begins to build, creating a free energy backpressure $\left(\Delta \mathrm{G}_{\mathrm{PMF}}\right)$ against the pumps, gradually slowing $\mathrm{JO}_{2}, \mathrm{Je}^{-}$flow, and $J \mathrm{H}^{+} \uparrow .(C)$ Eventually, the backpressure increases to the point that it counterbalances the proton pumps, at which point $\mathrm{JO}_{2}, \mathrm{Je}^{-}$flow, and $J \mathrm{H}^{+} \uparrow$ decrease to zero. $(D)$ In mitochondria, basal proton conductance back into the matrix $\left(J \mathrm{H}^{+} \downarrow\right)$ prevents the $\Delta \mathrm{G}_{\mathrm{PMF}}$ from reaching max, thereby allowing $\mathrm{JO}_{2}, \mathrm{Je}^{-}$flow, and $J \mathrm{H}^{+} \uparrow$ to proceed at a rate equivalent to the rate of $J \mathrm{H}^{+} \downarrow$. (E) Activation of ATP synthase (complex V) by addition of ADP accelerates proton conductance, thereby lowering $\Delta \mathrm{G}_{\mathrm{PMF}}$ and thus increasing $J \mathrm{O}_{2}, \mathrm{Je}^{-}$flow, and $J \mathrm{H}^{+} \uparrow$ accordingly. $(F)$ As $[\mathrm{ATP}] /[\mathrm{ADP}]+\left[\mathrm{P}_{\mathrm{i}}\right]$ increases, the free energy associated with ATP hydrolysis $\left(\Delta \mathrm{G}_{\mathrm{ATP}}\right)$ increases and creates back pressure on the ATP synthase, gradually slowing the rate of ATP synthesis, causing $\Delta \mathrm{G}_{\text {redox }}$ to climb and $\mathrm{JO}_{2}, \mathrm{Je}^{-}$flow, and $J \mathrm{H}^{+} \uparrow$ to slow accordingly back to the rate driven by basal proton conductance. Cyt $c$, Cytochrome $c$. 
P.D. Neufer

brane is slightly leaky to protons. This means that $\Delta \mathrm{G}_{\mathrm{PMF}}$ never reaches the level necessary to completely oppose $\Delta \mathrm{G}_{\text {redox }}$ (i.e., the brake is never fully depressed), but is at some lower level that is determined by the rate at which protons are conducting back into the matrix (Fig. 3D). What accounts for the proton leak is not entirely clear, although a significant portion is thought to be mediated by the adenine nucleotide translocase (Brand et al. 2005; Divakaruni and Brand 2011). Regardless of the mechanism, this "idling" of mitochondria is analogous to the idling of an engine, occurs in every mitochondrion in every cell, and accounts for as much as $25 \%$ of basal energy expenditure (Rolfe et al. 1999).

\section{Using Membrane Potential to Generate Energy Charge}

Having generated a steady-state $\Delta \mathrm{G}_{\mathrm{PMF}}$ from the $\Delta \mathrm{G}_{\text {redox }}$ for the $\mathrm{O}_{2} / 2 \mathrm{H}_{2} \mathrm{O}$ to $\mathrm{NAD}^{+} /$ $\mathrm{NADH}$ span, the system is now poised to use the $\Delta \mathrm{G}_{\mathrm{PMF}}$ to drive other reactions, the most prominent of which is the synthesis of ATP. Again, to understand the different free energy forces at play, it is most useful to continue the thought experiment and to imagine a cell that lacks mitochondria and thus, energetically, has yet to be brought to life. At $\mathrm{pH}=7.0$ and an approximate physiological $\mathrm{Mg}^{2+}$ concentration of $10^{-2} \mathrm{M}$, the apparent equilibrium constant for the hydrolysis of ATP is $10^{5} \mathrm{M}$ - meaning that the reaction is favored to the right with much greater [ADP] than [ATP] at equilibrium. Using typical cytoplasmic concentrations of $10^{-3} \mathrm{M}$ ADP and $10^{-2} \mathrm{M} \mathrm{P}_{\mathrm{i}}$, the concentration of ATP at equilibrium will only be $10^{-10} \mathrm{M}$ (Nicholls and Ferguson 2013). To shift the reaction away from equilibrium in favor of ATP therefore requires an input of energy. Enter the newly charged mitochondria and the ATP synthase enzyme. By providing another path for protons to conduct back into the mitochondrial matrix, the $\mathrm{F}_{\mathrm{o}} / \mathrm{F}_{1}$ ATP synthase uses the $\Delta \mathrm{G}_{\mathrm{PMF}}$ to drive the phosphorylation of ADP (Stock et al. 1999), accelerating rates of proton conductance, electron transport, and $\mathrm{O}_{2}$ consumption accordingly. Again, starting from scratch (i.e., very low $\left.[\mathrm{ATP}] /[\mathrm{ADP}]+\left[\mathrm{P}_{\mathrm{i}}\right]\right)$, the initial rate of proton conductance through the ATP synthase, and thus drop in $\Delta \Psi$ (i.e., release of brake), will be a function of the maximal activity of the ATP synthase enzyme. However, as the ratio of $[\mathrm{ATP}] /[\mathrm{ADP}]+\left[\mathrm{P}_{\mathrm{i}}\right]$ increases, the departure from equilibrium generates a new chemical Gibbs free energy for ATP hydrolysis $\left(\Delta \mathrm{G}_{\mathrm{ATP}}\right)$ (Fig. 3E), which will gradually build, creating product feedback pressure on the ATP synthase and the $\Delta \mathrm{G}_{\mathrm{PMF}}$ driving it. Proton conductance therefore begins to slow, causing $\Delta \mathrm{G}_{\mathrm{PMF}}$ to again gradually increase and respiration to gradually slow until the maximal $[\mathrm{ATP}] /[\mathrm{ADP}]+\left[\mathrm{P}_{\mathrm{i}}\right]$ that can be generated by the OXPHOS system is achieved (i.e., when $\left.\Delta \mathrm{G}_{\mathrm{ATP}}=\Delta \mathrm{G}_{\mathrm{PMF}}\right)$ (Fig. $3 \mathrm{~F}$ ). At this point, proton conductance is minimal through the ATP synthase and the mitochondria are therefore back to their idling rate of respiration determined by the rate of proton leak.

To summarize, the high reduction potential of the $\mathrm{O}_{2} / \mathrm{H}_{2} \mathrm{O}$ redox couple generates the biological electrical current that powers the mitochondria. The free energy difference across the $\mathrm{O}_{2} / \mathrm{H}_{2} \mathrm{O}$ and $\mathrm{NAD}^{+} / \mathrm{NADH}$ redox span $\left(\Delta \mathrm{G}_{\text {redox }}\right)$ is used to generate a $\Delta \mathrm{p}$ across the mitochondrial inner membrane, which in turn is used by the ATP synthase to drive ADP phosphorylation. Two regulators on the system prevent the wide open flow of electrons: (1) $\Delta \mathrm{p}$ (primarily the $\Delta \Psi$ component), which regulates proton pumping and thus electron flow; and (2) $[\mathrm{ATP}] /[\mathrm{ADP}]+\left[\mathrm{P}_{\mathrm{i}}\right]$, which regulates proton conductance through the ATP synthase and therefore $\Delta \Psi$. Recognize that the rate of mitochondrial respiration in response to an increase in $[\mathrm{ADP}]$ increases, not in an attempt to restore $\Delta \Psi$, but precisely because $\Delta \Psi$ decreases as an outcome of the increased $\mathrm{H}^{+}$conductance through ATP synthase. Thus, the mitochondrial ETS is a continuously operating "charged battery," poised to respond instantaneously to any change in proton conductance. As ATP synthase accounts for most of the dynamic range of proton conductance, it should therefore be apparent that the mitochondrial ETS is a demand-based system largely regulated by the rate of ATP usage. 


\section{UTILIZING THE CHARGE}

As mentioned above, under standard conditions and $\mathrm{pH}=7$, the hydrolysis of ATP is heavily favored with an apparent equilibrium constant of $10^{5} \mathrm{M}$. To give some context to the magnitude of energy conversion by the mitochondria, the OXPHOS system is capable of maintaining a mass action ratio for the ATP hydrolysis reaction of as low as $10^{-5} \mathrm{M}$, or a full ten orders of magnitude away from the equilibrium constant. It is the free energy associated with this displacement from equilibrium, given by the Gibbs energy equation (for derivation, see Nicholls and Ferguson 2013), which allows ATP hydrolysis to drive otherwise thermodynamically unfavorable processes (e.g., $>10,000$-fold $\mathrm{Ca}^{2+}$ gradient between sarcoplasmic reticulum [SR] and cytosol generated by SR $\mathrm{Ca}^{2+}$-ATPase, 20-fold $\mathrm{Na}^{+}$gradient at plasma membrane-generated $\mathrm{Na}^{+} / \mathrm{K}^{+}$ATPase, etc.). OXPHOS, therefore, energetically "brings the cell to life" by providing the $\Delta \mathrm{G}_{\mathrm{ATP}}$ necessary to establish and maintain the displacement from equilibrium for hundreds, if not thousands, of reactions.

At this juncture, there are three important points to emphasize. The first has already been alluded to; the magnitude of displacement from equilibrium for any chemical process $(A \rightarrow B)$ coupled to the hydrolysis of ATP is a function of the magnitude of Gibbs energy $\left(\Delta \mathrm{G}_{\mathrm{ATP}}\right)$ available to drive that displacement. This is because as $\mathrm{A}$ is converted to $\mathrm{B}$ and the reaction displaced from equilibrium, the Gibbs energy arising from that displacement (i.e., $-\Delta G$ favoring $\mathrm{B} \rightarrow \mathrm{A}$ ) builds until it counterbalances the positive Gibbs energy available from ATP hydrolysis, creating a static head (analogous to that mentioned earlier). In living cells, however, virtually all reactions or processes displaced from equilibrium will spontaneously re-equilibrate at a slow rate. Maintaining the displacement from equilibrium of any reaction coupled to ATP therefore requires a constant input of Gibbs energy, or $\Delta \mathrm{G}_{\mathrm{ATP}}$. The net result, rather than a static head, is a steady-state homeostasis in which the rate of loss of product draws an equal rate of replacement at the expense of ATP usage. Maintaining homeostasis undoubt- edly accounts for a significant portion of basal mitochondrial respiratory activity and overall metabolic rate, the second point to emphasize. Third, any stimulus that dissipates a disequilibrium created and maintained by ATP will correspondingly accelerate the rate of ATP usage until the disequilibrium is re-established, further emphasizing how the respiratory system is governed by and continuously adjusting to energy demand.

\section{ATP Use during Exercise}

The transition from rest to exercise imposes an energetic challenge that is unique to skeletal muscle cells compared with most other cell types, owing to the heavy increase in myosin ATPase and SR $\mathrm{Ca}^{2+}$ ATPase activities that occur with contractile activity. Although difficult to directly measure, relative steady-state rates of ATP usage are estimated to increase to $\sim 1.5 \mu \mathrm{mol} \cdot \mathrm{g} \mathrm{muscle}^{-1} \cdot \mathrm{s}^{-1}$, a 50 - to 100 fold increase over baseline, in well-trained humans during heavy cycling exercise (i.e., 3.5 L $\cdot \min ^{-1} \mathrm{VO}_{2}$ ). ATP concentration of mammalian muscle is $\sim 7-8 \mu \mathrm{mol} \cdot \mathrm{g}_{\text {muscle }}{ }^{-1}$, enough to last only a few seconds. Muscle ATP concentration, however, rarely declines during exercise except under heavy workloads at or near exhaustion, illustrating the remarkable capacity of the ATP synthesis pathways to keep pace with demand in muscle (Meyer and Wiseman 2012).

The importance of maintaining ATP concentration is further emphasized by considering the free energy thresholds required to maintain cell function. For example, during incremental exercise to exhaustion in humans, muscle $\Delta \mathrm{G}_{\text {ATP }}$ declines from $\sim 64 \mathrm{~kJ} \cdot \mathrm{mole}^{-1}$ to $\sim 50 \mathrm{~kJ} \cdot \mathrm{mole}^{-1}$ (Jeneson and Bruggeman 2004). A drop of only $2 \mathrm{~kJ} \cdot$ mole $^{-1}$ more would limit the ability of the SR $\mathrm{Ca}^{2+}$-ATPase to resequester $\mathrm{Ca}^{2+}$ after contraction against the gradient normally still present between the SR and cytosol, and the ability of the $\mathrm{Na}^{+} / \mathrm{K}^{+}$ATPase pump to reestablish the sodium gradient across the sarcolemma membrane (Chen et al. 1998; Meyer and Wiseman 2012). Thus, in a sense, fatigue is necessary to prevent muscle cells from committing energetic suicide. 
P.D. Neufer

\section{Pathways for ATP Production}

How then is [ATP] and $\Delta \mathrm{G}_{\mathrm{ATP}}$ maintained in muscle during exercise? Given the emphasis of this review, the seemingly obvious answer is from the increase in mitochondrial OXPHOS activity reacting automatically to the increase in ATPase rate. Indeed, in isolated mitochondria at $37^{\circ} \mathrm{C}, \mathrm{O}_{2}$ consumption increases to a new steady-state rate within just a few seconds after a stepwise addition of ADP. However, the response time to achieve a steady-state rate of $\mathrm{O}_{2}$ consumption in muscle during a rest to submaximal exercise transition in humans can be 30 sec or longer (Rossiter et al. 1999), implying that the energy coupling pathways are more complicated in vivo. This is likely by necessity as mitochondrial volume is estimated to be $\sim 12 \%$ and $8 \%$ of the cytoplasmic volume in type I and type II muscle fibers from humans (Dahl et al. 2015), making it spatially challenging to directly couple sites of ATP usage to ATP resynthesis (i.e., referred to as mitochondrial resistance to energy transfer). In 1988, Meyer (1988) proposed that this problem is overcome by the presence of the creatine shuttle. In striated muscle, creatine kinase $(\mathrm{CK})$ catalyzes the reversible reaction:

$$
\mathrm{ADP}+\mathrm{PCr} \rightleftarrows \mathrm{Cr}+\mathrm{ATP}
$$

with a standard equilibrium constant $\left(\mathrm{K}_{\mathrm{CK}}\right)$ of $\sim 150$ (Golding et al. 1995). Total CK activity is high in the cytosol, indicating that the reaction is likely near equilibrium under most circumstances. In the cytosol of a resting myofiber, the concentration of creatine is over 100-fold higher than ADP, meaning any small increase in [ADP] will generate a much larger increase in $[\mathrm{Cr}]$, effectively amplifying and distributing the signal. Once reaching the mitochondria, the increase in $[\mathrm{Cr}]$ is converted back to an increase in [ADP] by CK localized in the mitochondrial intermembrane space (Wallimann et al. 2011), increasing the sensitivity of OXPHOS to cytosolic changes in [ADP] (Perry et al. 2011). Thus, similar to a capacitor in an electrical circuit, the creatine shuttle serves as a metabolic capacitor-an immediately available source of stored energy that is discharged in parallel with the activation of the OXPHOS system. In contrast to the CK system, the mitochondrial OXPHOS system has little metabolic capacitance (i.e., stored ATP), instead relying on the regulation of proton conductance to generate energy. Because the two systems are intimately connected through the exchange of adenine nucleotides, the net effect is that any stepwise increase ATPase activity will elicit an increase in flux through both the CK (i.e., decrease in [PCr]) and mitochondrial OXPHOS (i.e., measured as $\mathrm{O}_{2}$ consumption) systems, both of which will occur over equal but opposite exponential time courses until a steady-state balance of flux is achieved. The model predicts that the time required to achieve a new steady state varies linearly with the total creatine pool (i.e., the size of the capacitor) and inversely with mitochondrial density (i.e., the resistance to energy transfer) (Meyer and Wiseman 2012), predictions that have been confirmed experimentally (Glancy et al. 2008). Therefore, the integration between the two systems ensures that the response to any increase in ATPase rate is both rapid and sustained, insuring the maintenance of $\Delta \mathrm{G}_{\mathrm{ATP}}$.

It is essential to recognize from the preceding that all pathways of ATP synthesis are integrated with one another in real time. For example, imagine a cell devoid of mitochondria that is relying exclusively on glycolysis for ATP production. At rest, steady-state basal rates of ATPase activity and flux through glycolysis will be balanced, generating steady-state concentrations of CK shuttle components. If fully functioning mitochondria are then introduced, the force of the OXPHOS system will drive the ATP/ADP ratio higher and distribute the increase in energy charge throughout the cell via the $C K$ shuttle according to $K_{C K}(\downarrow[A D P]$, $\uparrow[\mathrm{PCR}], \downarrow[\mathrm{Cr}], \uparrow[\mathrm{ATP}])$, providing additional charge to the capacitor. ATPase and ATP synthesis rates will still be balanced (i.e., demand not changed), but the source of ATP synthesis will now be distributed between glycolysis and OXPHOS. If the ATPase rate is increased, as occurs with the onset of exercise, flux through the CK shuttle, glycolysis, and OXPHOS path- 
ways will increase simultaneously until a new integrated steady-state balance of fluxes is achieved, again on an exponential time course determined by the size of the creatine pool and the mitochondrial density. Last, exercise physiology texts tend to present the activation of ATP synthesis pathways in response to exercise in a sequential order from the most rapidly activated/shortest lasting (i.e., ATP/PCr) to intermediately activated/lasting (i.e., glycolysis) to the most slowly activated/longest lasting (i.e., OXPHOS). This approach, unfortunately, fails to capture the integrated nature of the distribution and maintenance of energy charge that occurs in cells in response to exercise.

\section{FACTORS AFFECTING MITOCHONDRIAL BIOENERGETIC EFFICIENCY}

Evolution undoubtedly favored maximizing the efficiency of OXPHOS to protect against fuel reserves becoming depleted while hunting for the next meal, or for that matter to prevent from becoming the next meal. It should be apparent from the previous sections, however, that the ETS, by its very nature, is not $100 \%$ efficient. Basal proton conductance represents a partial loss of the potential maximum $\Delta \mathrm{G}_{\mathrm{PMF}}$ available to drive $\Delta \mathrm{G}_{\mathrm{ATP}}$, energy that is instead released as heat. The $\mathrm{JO}_{2}$ that results from proton leak, known as state 4 respiration, is known as "uncoupled" respiration because it represents the rate of proton conductance not directly coupled to ATP synthesis (state 3 respiration). An increase in state 4 respiration, or a lower respiratory coupling ratio (i.e., state $3 \mathrm{JO}_{2} /$ state 4 $\mathrm{JO}_{2}$ ), is often interpreted as indicative of a decrease in OXPHOS efficiency. However, proton leak across the mitochondrial inner membrane is driven by $\Delta \Psi$, increasing nonlinearly with increasing $\Delta \Psi$, but decreasing to near zero as ADP-stimulated respiration increases (i.e., as $\Delta \Psi$ decreases) (Korshunov et al. 1997). This insures that OXPHOS is most efficient when mitochondria are synthesizing ATP and conversely that more of the potential energy is diverted to heat production at rest when ATP demand is low (Lark et al. 2016).
Nevertheless, with the emergence of obesity and related diseases in Western societies, there is great interest in the potential therapeutic efficacy of targeting uncoupling in mitochondria to increase nonproductive energy expenditure. Hibernating animals use uncoupling to their advantage, increasing proton conductance in brown adipose tissue (BAT) mitochondria by inducing and activating uncoupling protein 1 (UCP1) to generate heat during the winter (Nicholls 2001; Cannon and Nedergaard 2004). Humans have on average only 50-80 g of BAT, which theoretically could increase energy expenditure by $\sim 20 \%$ if fully activated (Cypess et al. 2009), although recent studies have failed to support this contention (Blondin et al. 2015; Jensen 2015). Beige (or brite) cells are another type of UCP1-positive thermogenic adipocyte induced within subcutaneous white adipose tissue in response to a variety of factors, including cold exposure and exercise (Wu et al. 2012; Stanford and Goodyear 2016). Whether beiging can increase energy expenditure in humans sufficient to induce weight loss is also as yet unclear (Kusminski et al. 2016). UCP2 and UCP3, two related uncoupling proteins expressed in a variety of cell types, also catalyze an increase in proton conductance, but their role appears to be in protecting against oxidative stress rather than adaptive thermogenesis (Divakaruni and Brand 2011). Chemically uncoupling mitochondria with a protonophore, such as 2,4-dinitrophenol (DNP), has long been known to be an effective weight-loss treatment. DNP, however, was banned in the late 1930s because of its narrow margin between therapeutic efficacy and fatal hyperthermia (Colman 2007). The recent development of chemical uncouplers with broader pharmacodynamic ranges offer some therapeutic promise (Lou et al. 2007; Perry et al. 2013), but must be balanced against the potential negative impact on $\Delta \mathrm{G}_{\text {ATP }}$ and downstream bioenergetic and thermal regulation. Proton "slip" (electron transport without proton pumping) (Brand et al. 1994) and fatty acid flip-flop (Garlid et al. 1996) are other potential means of uncoupling, but these mechanisms remain controversial (Brand and $\mathrm{Ni}$ cholls 2011). Finally, it appears that cells have 
P.D. Neufer

their own mechanism for naturally balancing energy supply and energy demand. The ETS, as well as other dehydrogenase enzymes (e.g., pyruvate dehydrogenase complex), leak electrons and produce $\mathrm{H}_{2} \mathrm{O}_{2}$ when under-elevated "reducing pressure" (i.e., as a release valve when substrate supply outpaces demand). The $\mathrm{H}_{2} \mathrm{O}_{2}$ is, in turn, enzymatically reduced to water via redox-buffering circuits that ultimately draw electrons from NADPH. In the mitochondria, the regeneration of NADPH from $\mathrm{NADP}^{+}$is catalyzed largely by nicotinamide nucleotide transhydrogenase (NNT), a mitochondrial inner membrane protein that uses the membrane potential to generate and maintain a high $\mathrm{NADPH} / \mathrm{NADP}^{+}$ratio, analogous to ATP synthase maintaining a high ATP/ADP ratio. Continuous cycling of such redox circuits and, therefore, proton flux through NNT appears to represent a significant source of energy expenditure and a natural means by which cells balance energy supply with energy demand (Fisher-Wellman et al. 2015).

\section{CONCLUDING REMARKS}

Thermodynamics and bioenergetics are not the easiest concepts to grasp. This review uses the approach of considering how energy charge is first established and distributed to bring cells to life. The overriding principle is nonequilibrium thermodynamics, that is, how the natural driving force of reduction potential of the $\mathrm{O}_{2} /$ $\mathrm{H}_{2} \mathrm{O}$ redox couple is transformed to other electrochemical $\left(\Delta \mathrm{G}_{\mathrm{PMF}}\right)$ and chemical $\left(\Delta \mathrm{G}_{\mathrm{ATP}}\right)$ driving forces that are used to create and sustain the displacement from equilibrium that constitutes life for cells. Willis et al. (2016) have recently proposed a hydraulic analog model of OXPHOS to help conceptualize the interaction of the various driving forces that the reader may find helpful. For more in-depth coverage of bioenergetics, the reader is referred to Bioenergetics IV by Nicholls and Ferguson (2013).

Mitochondrial and cellular bioenergetics are foundational to understanding how cells sense and respond to the energetic challenges imposed by exercise. Viewing cellular responses and adaptations to stressors related to health and disease in the context of the nonequilibrium thermodynamics and energetic driving forces is critical to guiding experimental design and data interpretation.

\section{REFERENCES}

Blondin DP, Labbe SM, Phoenix S, Guerin B, Turcotte EE, Richard D, Carpentier AC, Haman F. 2015. Contributions of white and brown adipose tissues and skeletal muscles to acute cold-induced metabolic responses in healthy men. J Physiol 593: 701-714.

Brand MD, Nicholls DG. 2011. Assessing mitochondrial dysfunction in cells. Biochem J 435: 297-312.

Brand MD, Chien LF, Diolez P. 1994. Experimental discrimination between proton leak and redox slip during mitochondrial electron transport. Biochem J 297: 27-29.

Brand MD, Pakay JL, Ocloo A, Kokoszka J, Wallace DC, Brookes PS, Cornwall EJ. 2005. The basal proton conductance of mitochondria depends on adenine nucleotide translocase content. Biochem J 392: 353-362.

Cannon B, Nedergaard J. 2004. Brown adipose tissue: Function and physiological significance. Physiol Rev 84: $277-$ 359.

Chen W, London R, Murphy E, Steenbergen C. 1998. Regulation of the $\mathrm{Ca}^{2+}$ gradient across the sarcoplasmic reticulum in perfused rabbit heart. $\mathrm{A}^{19} \mathrm{~F}$ nuclear magnetic resonance study. Circ Res 83: 898-907.

Colman E. 2007. Dinitrophenol and obesity: An early twentieth-century regulatory dilemma. Regul Toxicol Pharmacol 48: 115-117.

Cypess AM, Lehman S, Williams G, Tal I, Rodman D, Goldfine AB, Kuo FC, Palmer EL, Tseng YH, Doria A, et al. 2009. Identification and importance of brown adipose tissue in adult humans. N Engl J Med 360: 1509-1517.

Dahl R, Larsen S, Dohlmann TL, Qvortrup K, Helge JW, Dela F, Prats C. 2015. Three-dimensional reconstruction of the human skeletal muscle mitochondrial network as a tool to assess mitochondrial content and structural organization. Acta Physiol (Oxf) 213: 145-155.

Divakaruni AS, Brand MD. 2011. The regulation and physiology of mitochondrial proton leak. Physiology (Bethesda) 26: 192-205.

Fisher-Wellman KH, Lin CT, Ryan TE, Reese LR, Gilliam LA, Cathey BL, Lark DS, Smith CD, Muoio DM, Neufer PD. 2015. Pyruvate dehydrogenase complex and nicotinamide nucleotide transhydrogenase constitute an energy-consuming redox circuit. Biochem J 467: 271-280.

Garlid KD, Orosz DE, Modriansky M, Vassanelli S, Jezek P. 1996. On the mechanism of fatty acid-induced proton transport by mitochondrial uncoupling protein. $J$ Bio Chem 271: 2615-2620.

Glancy B, Barstow T, Willis WT. 2008. Linear relation between time constant of oxygen uptake kinetics, total creatine, and mitochondrial content in vitro. Am J Physiol Cell Physiol 294: C79-C87.

Golding EM, Teague WEJr, Dobson GP. 1995. Adjustment of $\mathrm{K}^{\prime}$ to varying $\mathrm{pH}$ and $\mathrm{pMg}$ for the creatine kinase, adenylate kinase and ATP hydrolysis equilibria permitting 
The Bioenergetics of Exercise

quantitative bioenergetic assessment. J Exp Biol 198: $1775-1782$.

Jeneson JA, Bruggeman FJ. 2004. Robust homeostatic control of quadriceps $\mathrm{pH}$ during natural locomotor activity in man. FASEB J 18: 1010-1012.

Jensen MD. 2015. Brown adipose tissue-Not as hot as we thought. J Physiol 593: 489.

Korshunov SS, Skulachev VP, Starkov AA. 1997. High protonic potential actuates a mechanism of production of reactive oxygen species in mitochondria. FEBS Lett 416: $15-18$.

Kusminski CM, Bickel PE, Scherer PE. 2016. Targeting adipose tissue in the treatment of obesity-associated diabetes. Nat Rev Drug Discov 15: 639-660.

Lark DS, Torres MJ, Lin CT, Ryan TE, Anderson EJ, Neufer PD. 2016. Direct real-time quantification of mitochondrial oxidative phosphorylation efficiency in permeabilized skeletal muscle myofibers. Am J Physiol Cell Physiol 311: C239-C245.

Lou PH, Hansen BS, Olsen PH, Tullin S, Murphy MP, Brand MD. 2007. Mitochondrial uncouplers with an extraordinary dynamic range. Biochem J 407: 129-140.

Meyer RA. 1988. A linear model of muscle respiration explains monoexponential phosphocreatine changes. Am J Physiol 254: C548-C553.

Meyer RA, Wiseman RW. 2012. The metabolic systems: Control of ATP synthesis in skeletal muscle. In ACSM's advanced exercise physiology, 2nd ed. (ed. Farrell PA, Joyner MJ, Caizzo VJ), pp. 368-378. Lippincott, Williams \& Wilkins, Baltimore.

Nicholls DG. 2001. A history of UCP1. Biochem Soc Trans 29: $751-755$.

Nicholls DG, Ferguson SJ. 2013. Bioenergetics 4. Elsevier, London.
Perry CG, Kane DA, Lin CT, Kozy R, Cathey BL, Lark DS, Kane CL, Brophy PM, Gavin TP, Anderson EJ, et al. 2011. Inhibiting myosin-ATPase reveals a dynamic range of mitochondrial respiratory control in skeletal muscle. Biochem J 437: 215-222.

Perry RJ, Kim T, Zhang XM, Lee HY, Pesta D, Popov VB, Zhang D, Rahimi Y, Jurczak MJ, Cline GW, et al. 2013. Reversal of hypertriglyceridemia, fatty liver disease, and insulin resistance by a liver-targeted mitochondrial uncoupler. Cell Metab 18: 740-748.

Rolfe DF, Newman JM, Buckingham JA, Clark MG, Brand MD. 1999. Contribution of mitochondrial proton leak to respiration rate in working skeletal muscle and liver and to SMR. Am J Physiol 276: C692-C699.

Rossiter HB, Ward SA, Doyle VL, Howe FA, Griffiths JR, Whipp BJ. 1999. Inferences from pulmonary $\mathrm{O}_{2}$ uptake with respect to intramuscular [ phosphocreatine] kinetics during moderate exercise in humans. J Physiol 518: 921932.

Stanford KI, Goodyear LJ. 2016. Exercise regulation of adipose tissue. Adipocyte 5: 153-162.

Stock D, Leslie AG, Walker JE. 1999. Molecular architecture of the rotary motor in ATP synthase. Science 286: 1700_ 1705.

Wallimann T, Tokarska-Schlattner M, Schlattner U. 2011. The creatine kinase system and pleiotropic effects of creatine. Amino Acids 40: 1271-1296.

Willis WT, Jackman MR, Messer JI, Kuzmiak-Glancy S, Glancy B. 2016. A simple hydraulic analog model of oxidative phosphorylation. Med Sci Sports Exerc 48: 990-1000.

Wu J, Bostrom P, Sparks LM, Ye L, Choi JH, Giang AH, Khandekar M, Virtanen KA, Nuutila P, Schaart G, et al. 2012. Beige adipocytes are a distinct type of thermogenic fat cell in mouse and human. Cell 150: 366-376. 


\section{$\&_{\mathrm{CSH}}^{\infty} \&$ Cold Spring Harbor

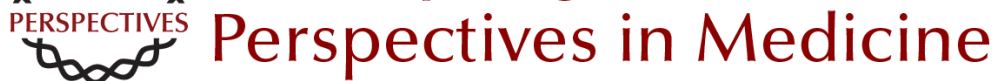

\section{The Bioenergetics of Exercise}

P. Darrell Neufer

Cold Spring Harb Perspect Med 2018; doi: 10.1101/cshperspect.a029678 originally published online May 10, 2017

\section{Subject Collection The Biology of Exercise}

Exosomes as Mediators of the Systemic

Adaptations to Endurance Exercise Adeel Safdar and Mark A. Tarnopolsky

Molecular Basis of Exercise-Induced Skeletal

Muscle Mitochondrial Biogenesis: Historical

Advances, Current Knowledge, and Future

Challenges

Christopher G.R. Perry and John A. Hawley

Exercise Metabolism: Fuels for the Fire Mark Hargreaves and Lawrence L. Spriet

Health Benefits of Exercise Gregory N. Ruegsegger and Frank W. Booth

Molecular Regulation of Exercise-Induced Muscle

Fiber Hypertrophy

Marcas M. Bamman, Brandon M. Roberts and Gregory R. Adams

Physiological Redundancy and the Integrative

Responses to Exercise Michael J. Joyner and Jerome A. Dempsey

On the Run for Hippocampal Plasticity C'iana Cooper, Hyo Youl Moon and Henriette van Praag

Molecular Basis for Exercise-Induced Fatigue: The Importance of Strictly Controlled Cellular $\mathrm{Ca}$

2+ Handling

Arthur J. Cheng, Nicolas Place and Håkan

Westerblad
Effects of Exercise and Aging on Skeletal Muscle Giovanna Distefano and Bret $H$. Goodpaster

Muscle-Adipose Tissue Cross Talk Kristin I. Stanford and Laurie J. Goodyear

Performance Fatigability: Mechanisms and Task Specificity

Sandra K. Hunter

Adaptations to Endurance and Strength Training David C. Hughes, Stian Ellefsen and Keith Baar

The Bioenergetics of Exercise

$P$. Darrell Neufer

Effects of Exercise on Vascular Function,

Structure, and Health in Humans

Daniel J. Green and Kurt J. Smith

Control of Muscle Metabolism by the Mediator

Complex

Leonela Amoasii, Eric N. Olson and Rhonda

Bassel-Duby

Theoretical and Biological Evaluation of the Link between Low Exercise Capacity and Disease Risk Lauren Gerard Koch and Steven L. Britton

For additional articles in this collection, see http://perspectivesinmedicine.cshlp.org/cgi/collection/ 